\title{
IKK $\beta$ in postnatal perichondrium remotely controls endochondral ossification of the growth plate through downregulation of MCP-5
}

\author{
K Kobayashi ${ }^{1}$, J Toguchida ${ }^{1}$, M Karin ${ }^{2}$ and T Kato $\mathrm{Jr}^{\star *, 1,3}$
}

I $\kappa$ B kinase $\beta(\mathrm{IKK} \beta)$ is a catalytic subunit of the IKK complex, which activates nuclear factor- $\kappa \mathrm{B}(\mathrm{NF}-\kappa \mathrm{B})$. Although its role in osteoclastogenesis is well established, the role of IKK $\beta$ in bone formation is poorly understood. Here, we report that conditional knockout of $I k k \beta$ in limb bud mesenchymal cells results in the upregulation of monocyte chemoattractant protein-5 (MCP-5) in the perichondrium, which in turn inhibits the growth of longitudinal bone by compromising chondrocyte hypertrophy and increasing the apoptosis of chondrocytes within the growth plate. Contrary to expectations, IKK $\beta$ in cells of chondrocyte or osteoblast lineage was dispensable for bone growth. On the other hand, ex vivo experiments confirmed the role of MCP-5 in the growth of longitudinal bone. Furthermore, an in vitro study demonstrated that the action of IKK $\beta$ on MCP-5 is cell autonomous. Collectively, our results provide evidence for a previously unrecognized role of IKK $\beta$ in the regulation of the growth plate that is mediated through stimulation-independent downregulation of MCP-5 in the perichondrium.

Cell Death and Differentiation (2015) 22, 852-861; doi:10.1038/cdd.2014.192; published online 19 December 2014

The $I_{\kappa} \mathrm{B}$ kinase (IKK) complex contains two catalytic subunits, $\mathrm{IKK} a$ and $\mathrm{IKK} \beta$, which are highly similar in sequence. ${ }^{1}$ In conjunction with the regulatory subunit, IKKy (also known as NEMO), the IKK complex transduces signals to downstream effectors. ${ }^{2}$ Among the downstream targets of the IKK complex, nuclear factor- $\kappa \mathrm{B}(\mathrm{NF}-\kappa \mathrm{B})$ is known to have a plethora of roles in immune and inflammatory response, cell growth, cell death and stress responses. ${ }^{3,4}$ In addition, recently, it has been reported that IKK $\beta$ targets additional substrates and regulates NF- $k$ Bindependent signaling. ${ }^{5,6}$ Because mice deficient for the gene encoding IKK $\beta$ die in midgestation, ${ }^{7-9}$ to investigate the function of IKK $\beta$ in vivo in tissue- and stage-specific settings, mice with a floxed $I k k \beta$ allele have been generated. ${ }^{10,11}$

The skeleton is an organ that not only supports and protects the body, but is also involved in other functions via communications with other organs. These communications render unanticipated complexities to skeletal patterning and to the specification/differentiation of skeletal cells during development. $^{12}$ The skeleton is composed of cartilage and bone, and the development of these two cell types is coordinated by a network of signaling pathways and transcription factors. ${ }^{13}$ Bone is remodeled by the coupling of two opposing processes: bone resorption and bone formation. During bone resorption, osteoclasts degrade mature bone tissue, whereas during bone formation, osteoblasts form new bone through a process called ossification. The development and activation of osteoclasts are well characterized at the genetic and molecular levels, ${ }^{14,15}$ and the role of IKK signaling in these processes has been established. ${ }^{16}$ In contrast, less is known about the role of IKK in osteoblast development.

In this study, we sought to explore the role of $\mathrm{IKK} \beta$ in bone formation through osteoblast- or chondrocyte-specific ablation of $I \mathrm{kk} \beta$. Although $\mathrm{IKK} \beta$ was dispensable for cells of either osteoblast or chondrocyte lineage, loss of IKK $\beta$ in limb bud mesenchymal cells resulted in the growth retardation of longitudinal bone. This effect was due to a reduced hypertrophy and increased apoptosis of chondrocytes in the growth plate. A search for the mechanism underlying this abnormality led to the finding that IKK $\beta$ suppresses the expression of $M c p-5$ (monocyte chemoattractant protein-5) in the perichondrium in a cell-autonomous manner. Based on these results, we suggest that the IKK $\beta-\mathrm{MCP}-5$ axis may regulate chondrocyte hypertrophy in parallel with the transforming growth factor- $\beta$ receptor type II (T $\beta$ RII)-MCP-5 axis, which was reported recently. ${ }^{17}$

\section{Results}

Loss of IKK $\beta$ in the osteoblast lineage does not affect bone remodeling. Bone remodeling depends on the orchestrated balance between bone formation and bone resorption. The role for IKK-NF- $\kappa$ B signaling in osteoclastogenesis is well established, ${ }^{16}$ but far less is known about role for IKK $\beta$ in bone formation. We therefore crossed $I k k \beta^{\mathrm{F} / \mathrm{F}}$ mice ${ }^{10}$ with mice expressing Cre recombinase under the control of type I collagen promoter elements. ${ }^{18}$ In the resulting $I k k \beta^{\mathrm{F} / \mathrm{F}}$;

\footnotetext{
${ }^{1}$ Department of Tissue Regeneration, Institute for Frontier Medical Sciences, Kyoto University, Kyoto 606-8507, Japan and ${ }^{2}$ Laboratory of Gene Regulation and Signal Transduction, Departments of Pharmacology and Pathology, School of Medicine, University of California San Diego, La Jolla, CA 92093-0723, USA

*Corresponding author: T Kato Jr, Current address: Department of Cell Growth and Differentiation, Center for iPS Cell Research and Application (CiRA), Kyoto University, 53 Kawahara-cho, Shogoin, Sakyo-ku, Kyoto 606-8507, Japan. Tel: +81 75751 4126; Fax: +81 75751 4646; E-mail: tkato @frontier.kyoto-u.ac.jp or tkato@ @ira.kyoto-u.ac.jp ${ }^{3}$ Current address: Department of Cell Growth and Differentiation, Center for iPS Cell Research and Application (CiRA), Kyoto University, 53 Kawahara-cho, Shogoin, Sakyo-ku, Kyoto 606-8507, Japan

Abbreviations: IKK, I $\kappa$ kinase; NF- $\kappa B$, nuclear factor- $-\mathrm{B}$; MCP-5, monocyte chemoattractant protein-5; T $\beta$ RII, TGF- $\beta$ receptor type II; TGF- $\beta 1$, transforming growth factor- $\beta 1$; BV/TV, bone volume/trabecular volume; TUNEL, terminal deoxynucleotidyl transferase-mediated dUTP-biotin nick-end labeling

Received 19.5.14; revised 23.10.14; accepted 28.10.14; Edited by G Melino; published online 19.12.14
} 
Col1a1-Cre (hereafter described as $I k k \beta^{\mathrm{Col} 1 \mathrm{KO}}$ ) mice, deletion of the $I k k \beta$ locus should occur specifically in mesenchymal bone cells through Cre recombination and can be assessed by PCR preferentially amplifying Ikkß DNA (Supplementary Figure S1a). ${ }^{19}$ Indeed, as shown in Supplementary Figures $\mathrm{S} 1 \mathrm{~b}$ and $\mathrm{c}$, the $I k k \beta \Delta$ fragment was amplified only from genomic DNA prepared from the bone of $I k k \beta^{\text {Col1kO }}$ mice, demonstrating the specificity of the recombination in bone. To quantify the efficiency of the deletion more accurately, we performed $\mathrm{GPCR}$ with a primer set that only amplifies the residual $I k k \beta$ locus ${ }^{19}$ and observed efficient $(78.5 \%)$ deletion of the $I k k \beta$ locus in primary osteoblasts of $I k k \beta^{\text {Col1KO }}$ mice (Figure 1a and Supplementary Figure S1a). Despite the efficient deletion of $I k k \beta$ in osteoblasts, $I k k \beta^{\mathrm{Col} 1 \mathrm{KO}}$ mice were a
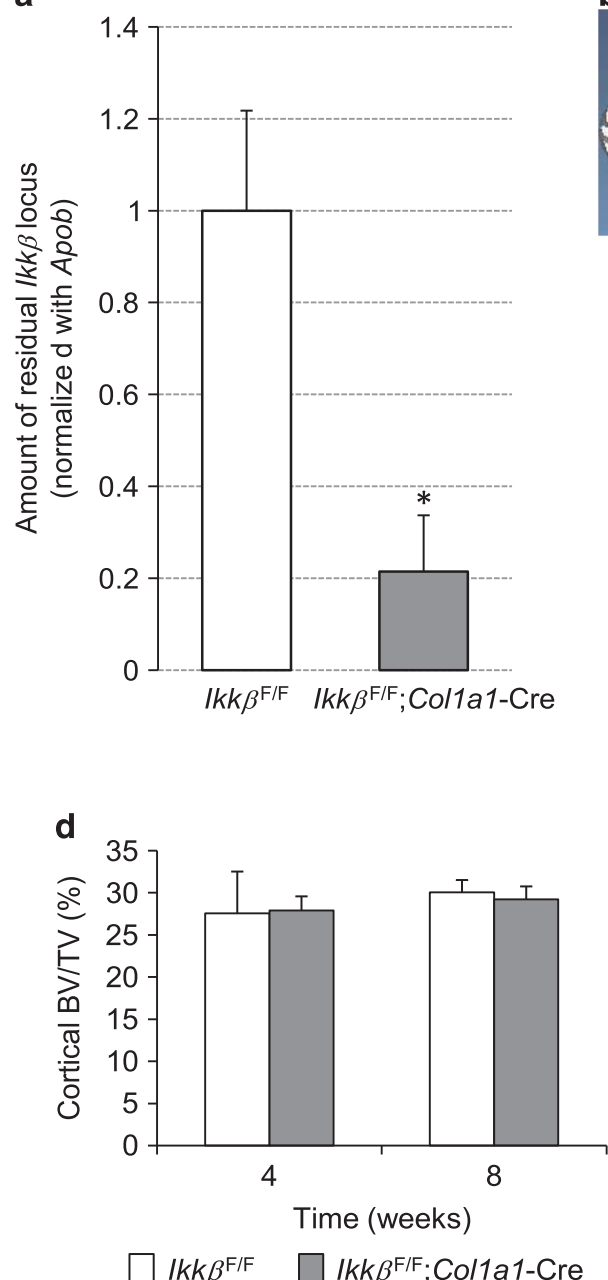

f

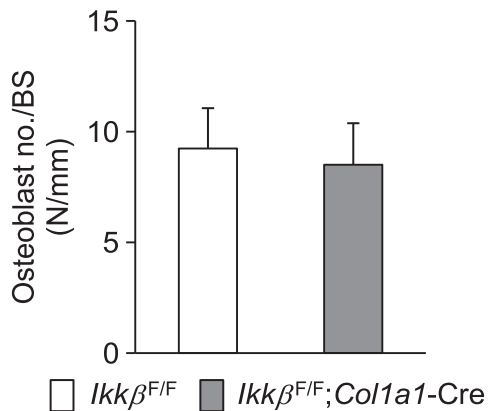

b

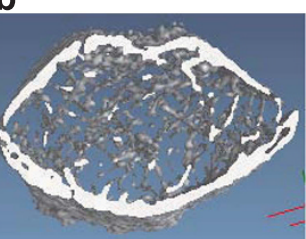

$I k k \beta^{\mathrm{F} / \mathrm{F}}$

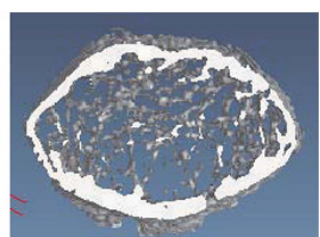

Ikk $\beta^{\mathrm{F} / \mathrm{F}}$;Col1a1-Cre
C

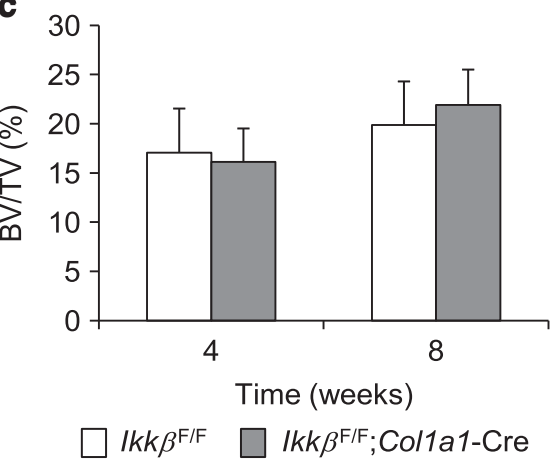

e

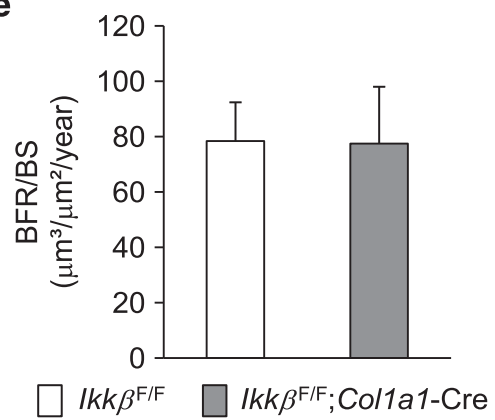

g

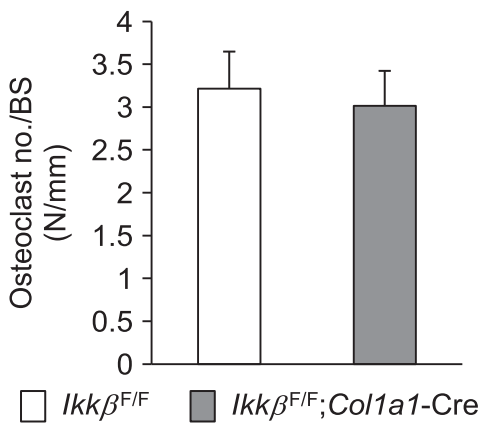

Figure $1 \quad I K K \beta$ in osteoblast lineage is dispensable for bone growth and remodeling during normal development. (a) The effect of deleting the IkK $\beta$ locus was examined using genomic DNA isolated from primary osteoblasts of the indicated mouse. Residual lkk $\beta$ locus was quantified by qPCR. (b) $\mu \mathrm{CT}$ images of the distal femur from 4-week-old $/ \mathrm{kk} \beta^{\mathrm{F} / \mathrm{F}}$ (control) and $I \mathrm{kk} \beta^{\mathrm{F} / \mathrm{F}}$;Col1a1-Cre mice. (c) Cancellous BV/TV in the distal femur of 4- and 8-week-old control and Ikk $\beta^{\mathrm{FF}}$;Col1a1-Cre mice ( $n=10$ in each group). (d) Cortical BVI TV in the distal femur of 4- and 8-week-old control and $I k k \beta^{F / F}$;Col1a1-Cre mice $(n=10$ in each group). (e) Bone formation rate was calculated with calcein double labeling $(n=10$ in each group). ( $\mathbf{f}$ and $\mathbf{g})$ Osteoblast and osteoclast numbers of 8 -week-old control and Ikk $\beta^{\mathrm{FF} F}$;Col1a1-Cre mice. ${ }^{*} P<0.001$, two-sided Student's $t$-test. Error bars \pm S.D. 
born at the expected Mendelian frequency, and the length of their crown-rump and long bones were the same as those of control mice until 8 weeks of age (Supplementary Figure S2). We next assessed the skeletal volume of $I k k \beta^{\text {Col1kO }}$ mice in detail using microcomputed tomography ( $\mu \mathrm{CT}$ ) (Figure 1b). $\mu \mathrm{CT}$ analysis of the secondary spongiosa of the distal femur revealed that bone volume in the cancellous and cortical bones of $I k k \beta^{\text {Col1 } 1 \mathrm{KO}}$ mice was not significantly different from that of control mice at age 4 weeks and even 8 weeks (Figures 1c and d). We further performed dynamic histomorphometric analysis by labeling the bones with calcein, a wellknown marker of bone formation, over 7 days. The bone formation rate of 8 -week-old $I k k \beta^{\text {Col1kO }}$ mice $\left(77.49 \mu \mathrm{m}^{3} / \mu \mathrm{m}^{2}\right.$ per year) was similar to that of control mice $\left(78.14 \mu \mathrm{m}^{3} / \mu \mathrm{m}^{2}\right.$ per year) (Figure 1e), as too was the number of osteoblasts and osteoclasts (Figures $1 \mathrm{f}$ and $\mathrm{g}$ ). These results indicate that $\mathrm{IKK} \beta$ in cells of osteoblast lineage is dispensable for normal bone growth.

Loss of IKK $\beta$ in osteoblast lineage does not affect bone loss induced by ovariectomy. As there was no abnormality in $I k k \beta^{\text {Col1 } 1 \mathrm{KO}}$ mice at physiological conditions, we next investigated the role of $\mathrm{IKK} \beta$ in osteoblast lineage during bone loss induced by ovariectomy. To mimic the bone loss in postmenopausal osteoporosis in humans, the ovariectomy mouse model has been widely used. ${ }^{20}$ We performed sham operation or ovariectomy to 12-week-old control and $I k k \beta^{\text {Col1KO }}$ mice and analyzed them 8 weeks later. $\mu \mathrm{CT}$ analysis revealed that cancellous bones in the distal femur were significantly decreased by ovariectomy compared with those of sham operated in both control and $I k k \beta^{\mathrm{Col} 1 \mathrm{KO}}$ mice (Figure $2 \mathrm{a}$ ). Yet, there was no significant difference in bone volume per trabecular volume (BV/TV) of ovariectomized $I \mathrm{kk} \beta^{\mathrm{Col} 1 \mathrm{KO}}$ mice compared with that of control ovariectomized mice (Figure $2 b$ ). These results in conjunction with those presented in Figure 1 indicate that IKK $\beta$ in cells of osteoblast lineage is dispensable not only under physiological conditions but also during postmenopausal osteoporosis.

Loss of IKK $\beta$ in limb bud mesenchymal cells compromises postnatal longitudinal bone growth. To examine the role of $\mathrm{IKK} \beta$ in endochondral ossification in vivo, we crossed the $1 \mathrm{kk} \beta^{\mathrm{F} / \mathrm{F}}$ mouse line with a transgenic mouse line expressing Cre recombinase under the control of Prx1 enhancer elements. ${ }^{21}$ Prx1-Cre transgenic mice express Cre recombinase in mesenchymal cells of the developing limb and parts of the skull but not in the spine or other organs. $I k k \beta^{\mathrm{F} / \mathrm{F}} ;$ Prx 1-Cre (hereafter described as $I k k \beta^{\mathrm{Prx} 1 \mathrm{KO}}$ ) mice were born at the expected Mendelian frequency and were viable and fertile. We confirmed the depletion of $I k k \beta$ mRNA in the growth plate of 2 -week-old $I k k \beta^{\text {Prx1KO }}$ mice compared with control mice (Figure $3 a$ ). I $k k \beta^{\text {Prx1KO mice had no skeletal }}$ abnormality at birth (Figures $3 b$ and $\mathrm{c}$ ). Although no significant difference in the length of lumbar vertebrae (L2-5) was observed, the long bones were shorter than those of control mice at 2 weeks of age and the difference lasted even at 8 weeks (Figures $3 d$ and e). These results indicate that IKK $\beta$ in the mesenchymal cells of developing limb bud, which are known to be the precursors of osteochondro progenitor cells, is involved in postnatal growth of the longitudinal bone.

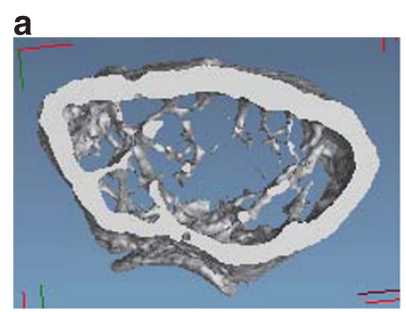

I $k k \beta^{\mathrm{F} / \mathrm{F}}$ sham

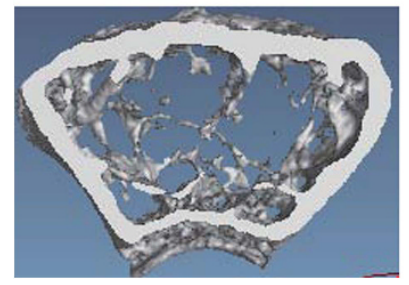

Ikk $\beta^{\mathrm{F} / \mathrm{F}} ; \mathrm{Col1a1-Cre} \mathrm{sham}$

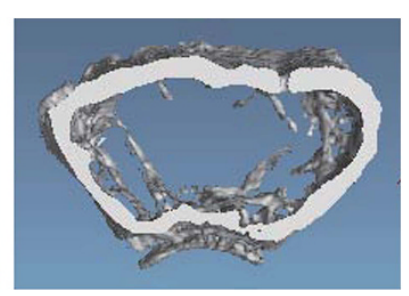

$I k k \beta^{\mathrm{F} / \mathrm{F}} \mathrm{OVX}$

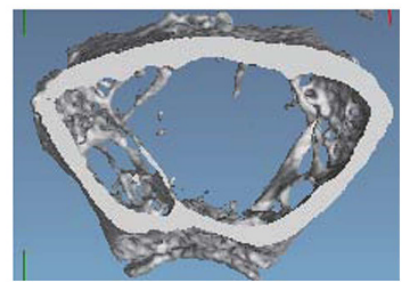

Ikk $\beta^{\mathrm{F} / \mathrm{F}} ;$ Col1a1-Cre OVX

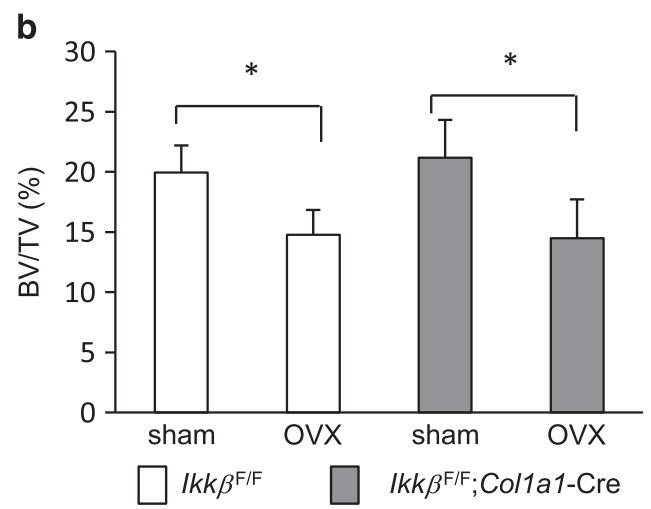

Figure $2 \mathrm{IKK} \beta$ in osteoblast is dispensable for cancellous bone loss induced by ovariectomy. (a) $\mu \mathrm{CT}$ images of the distal femur from adult control and $\mathrm{lkk} \beta^{\mathrm{F} / \mathrm{F}}$; Col1a1-Cre mice after ovariectomy (OVX). (b) Cancellous BV/TV in the distal femur of sham operated $\left(I k k \beta^{\mathrm{F} / \mathrm{F}}\right.$ sham) and ovariectomized ( $\left.I k k \beta^{\mathrm{F} / \mathrm{F}} \mathrm{OVX}\right)$ control and $I \mathrm{kk} \beta^{\mathrm{F} / \mathrm{F}}$; Col1a1-Cre mice ( $n=6$ in each group). ${ }^{\star} P<0.05$, two-sided Student's $t$-test. Error bars \pm S.D.

Loss of IKK $\beta$ in mesenchymal cells affects growth plate structure. We further investigated bone defects in $I k k \beta^{\text {Prx1kO }}$ mice. Histomorphometric analysis of proximal tibia from 2-week-old $I k k \beta^{\text {Prx1KO }}$ mice revealed a significant reduction in growth plate thickness owing to a reduction in thickness of the hypertrophic zone (Figures $4 \mathrm{a}$ and b). As shown in Figures $4 \mathrm{c}$ and $\mathrm{d}$, we confirmed the reduction in the hypertrophic zone by immunohistochemical analysis of type $X$ collagen. To further investigate the cause of chondrocyte abnormality at the growth plate of $I k k \beta^{\text {Prx } 1 \mathrm{KO}}$ mice, cell proliferation and apoptosis were assessed by BrdU staining and terminal deoxynucleotidyl transferase-mediated dUTPbiotin nick-end labeling (TUNEL) staining, respectively. For this purpose, tibial sections prepared from 2-week-old mice were studied. BrdU labeling demonstrated that BrdU-positive proliferating chondrocytes in $I k k \beta^{\mathrm{Prx} 1 \mathrm{KO}}$ and control mice were not significantly different (Figures $4 \mathrm{e}$ and $\mathrm{f}$ ). On the other hand, TUNEL staining demonstrated that chondrocyte apoptosis was significantly increased in the chondroosseus junction of $l k k \beta^{\mathrm{Prx} 1 \mathrm{KO}}$ mice compared with that of control mice 
a

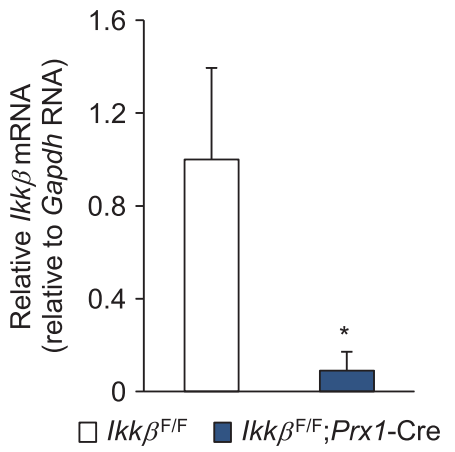

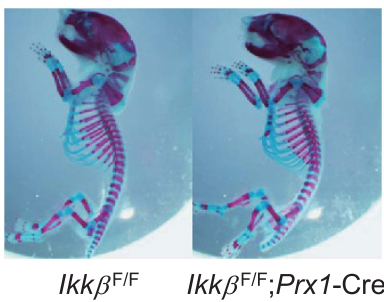

$I k k \beta^{\mathrm{F} / \mathrm{F}} \quad I k k \beta^{\mathrm{F} / \mathrm{F}} ; \operatorname{Prx1} 1-\mathrm{Cre}$

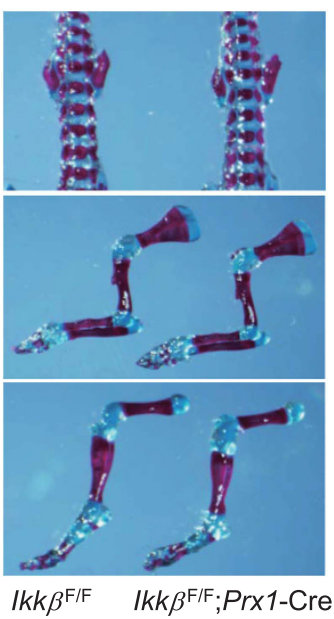

d
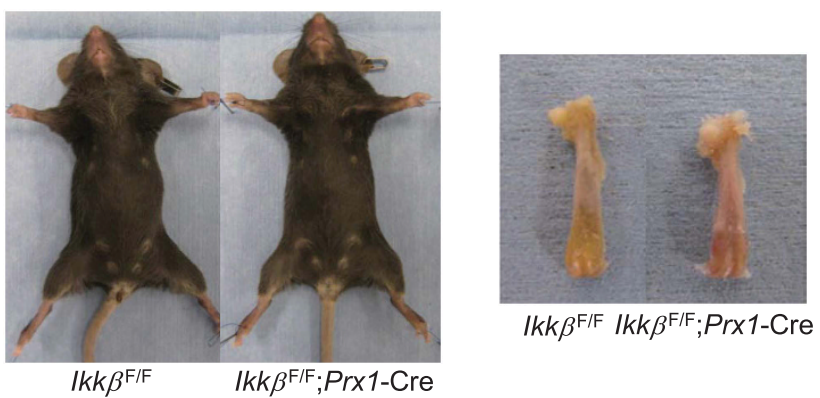

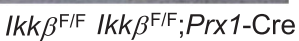

e

Lumber vertebrae (L2-5)
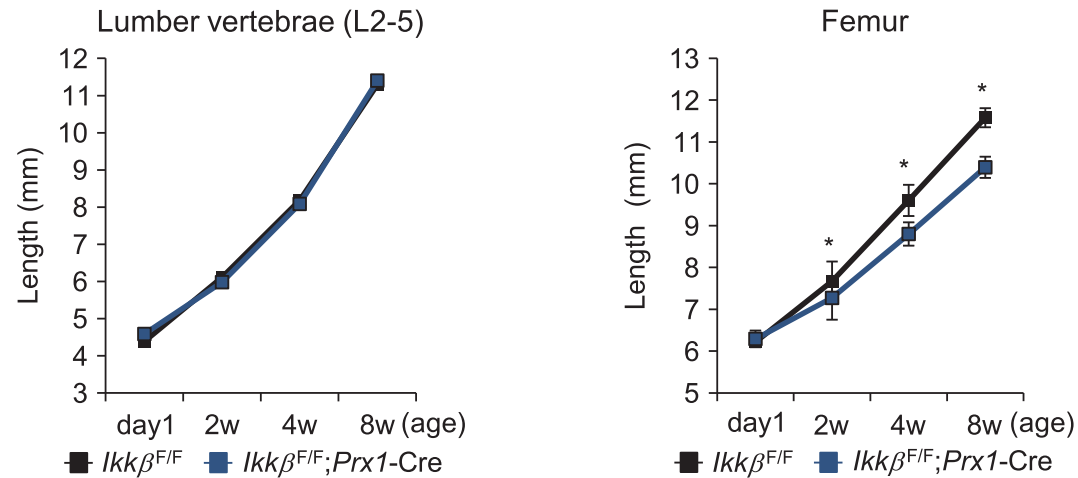

Figure 3 Phenotype of mesenchymal cell-specific $I k k \beta$ knockout mice. (a) $I k k \beta$ mRNA level in the growth plate of control and $I k k \beta{ }^{F / F} ;$ Prx 1 -Cre $(n=3$ in each group; ${ }^{*} P<0.001$, two-sided Student's $t$-test). Dissection of the growth plate and isolation of RNA was performed as described in the Materials and Methods section. (b) Skeletal preparation at P1 was stained with alcian blue and alizarin red. (c) Detailed skeletal morphology at P1. Lumber vertebrae (top panel), upper extremity (middle panel) and lower extremity (bottom panel). (d) Photograph of 8-week-old control and $I k k \beta^{\mathrm{F} F}$;Prx1-Cre mice (left panel) and femoral bone (right panel). Ikk $\beta^{\mathrm{F} / \mathrm{F}}$;Prx 1 -Cre mice exhibited postnatal short long bones. (e) The length of lumber vertebrae (L2-5) and femur of control and $I k k \beta^{F / F}$;Prx1-Cre mice from 1 day to 8 weeks. Although there was no significant difference in the length of lumbar vertebrae, the length of long bones was significantly shorter in $I k k \beta^{\mathrm{FF}} ;$ Prx 1 -Cre mice by 2 weeks of age and persisted at 8 weeks $(n=18$ in control and $n=20$ in $I k k \beta^{F / F} ;$ Prx 1 -Cre; ${ }^{*} P<0.01$, two-sided Student's $t$-test). Error bars \pm S.D.

(Figures $4 \mathrm{~g}$ and $\mathrm{h}$ ). These results indicate that the loss of IKK $\beta$ in mesenchymal cells of the limb bud inhibits chondrocyte hypertrophy through an increase in chondrocyte apoptosis in the growth plate.

No significant difference in cancellous and cortical BV/TV was observed between $I k k \beta^{\text {Prx1KO }}$ mice and control mice at 4 and 8 weeks of age according to $\mu \mathrm{CT}$ analysis of the distal femur (Supplementary Figures $\mathrm{S} 3 \mathrm{a}$ and $\mathrm{b}$ ). The bone formation rate and the number of osteoblasts and osteoclasts in 8-week-old $I k k \beta^{\text {Prx1KO }}$ mice did not show significant differences compared with control mice (Supplementary
Figures S3c, $d$ and e). These results indicate that the phenotype of $I k k \beta^{\text {Prx1KO }}$ mice is due to the defect in hypertrophic chondrocytes in the growth plate but not in bone remodeling.

Loss of IKK $\beta$ in chondrocytes does not cause bone growth retardation. It is known that appendicular and axial skeletons develop through endochondral ossification in mammals, and, in the primitive stage of this process, two distinct cell types, chondrocytes and perichondral cells, appear. $^{22}$ To dissect the contribution of the two cell types to 
a

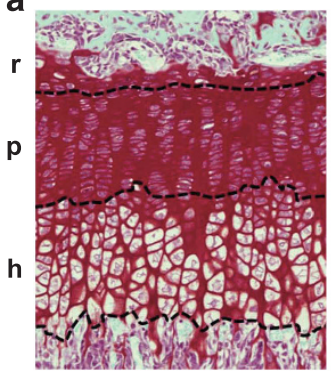

$I k k \beta^{\mathrm{F} / \mathrm{F}}$

C

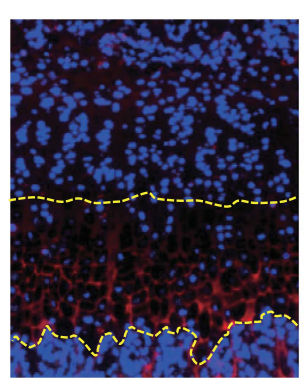

$1 k k \beta^{\mathrm{FIF}}$

e

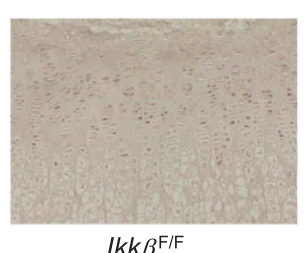

$I k k \beta^{\mathrm{F} / \mathrm{F}}$

g

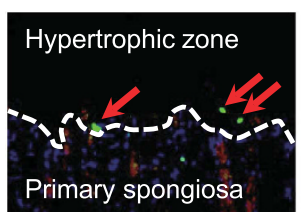

$I k k \beta^{\mathrm{F} / \mathrm{F}}$

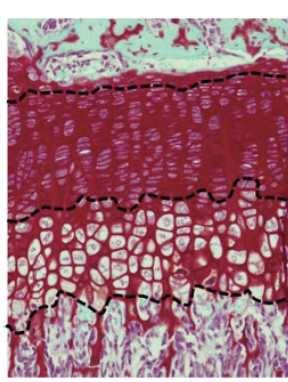

Ikk $\beta^{\mathrm{F} / \mathrm{F}} ; \operatorname{Prx1-Cre}$

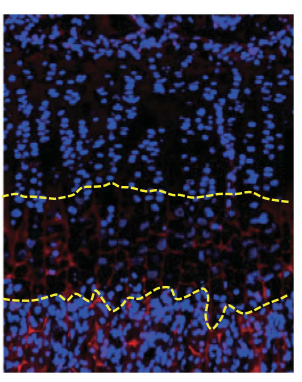

Ikk $\beta^{\mathrm{F} / \mathrm{F} ; P r x 1-C r e}$

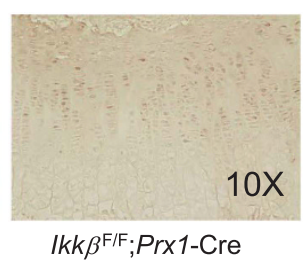

$I k k \beta^{\mathrm{F} / \mathrm{F}} ; \operatorname{Prx} 1-\mathrm{Cre}$ b
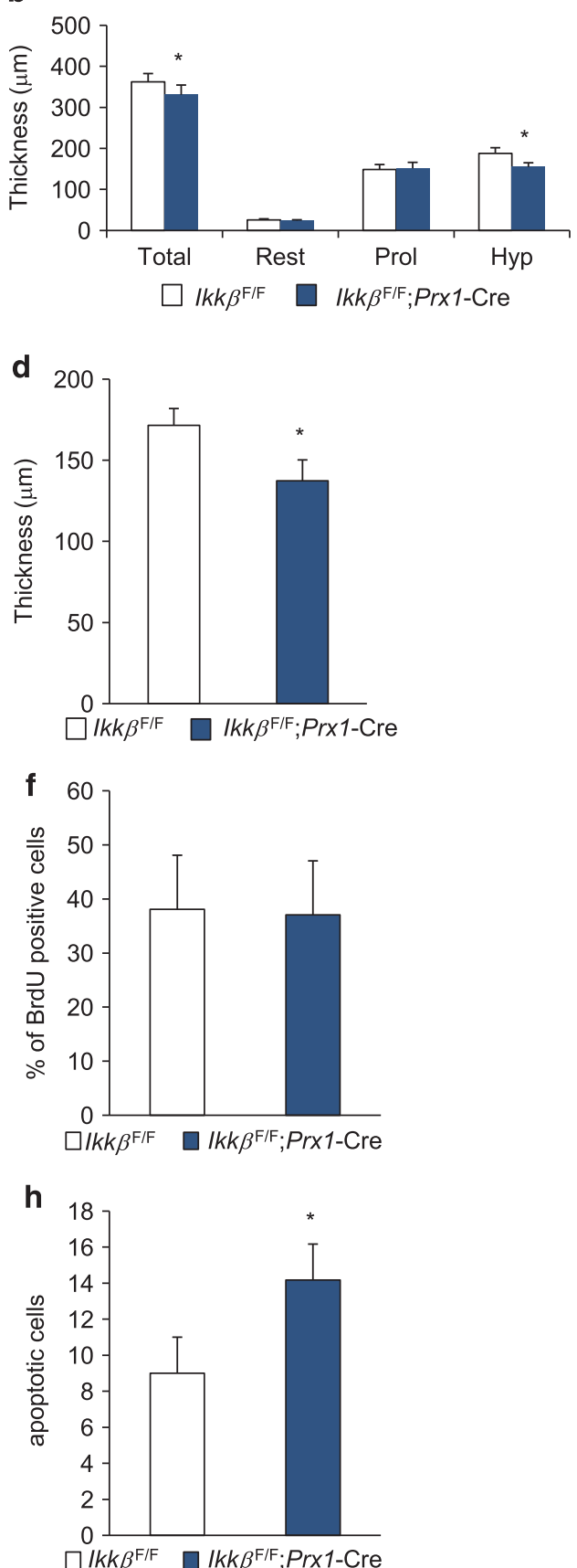

Figure 4 Loss of IKK $\beta$ in limb bud mesenchymal cells alters the growth plate structure. (a) Proximal tibial growth plates from 2-week-old mice were stained with safranin-O. A reduction in thickness of the growth plate was observed in $I k k \beta^{F / F} ;$ Prx 1-Cre mice. (b) Histomophometric analysis of the growth plate. The thickness of total growth plate was significantly shorter than that of controls $\left(n=8\right.$ in each group). (c) Tibiae from 2-week-old control and $I k k \beta^{\mathrm{F} / F} ;$ Prx 1 -Cre mice were immunostained for type $X$ collagen. (d) Thickness of the hypertrophic zone in Ikk $\beta^{\mathrm{F} / \mathrm{F}}$;Prx 1-Cre mice was significantly shorter than that of controls $\left(n=5\right.$ in each group). (e) Two-week-old control and Ikk $\beta^{\mathrm{F} / \mathrm{F}}$;Prx 1 -Cre mice were injected with BrdU labeling solution ( $1 \mathrm{ml} / 100 \mathrm{~g}$ body weight) at 20 and $4 \mathrm{~h}$ before killing, and proximal tibiae were immunostained for BrdU. (f) BrdU-positive cells were quantitatively represented ( $n=5$ in each group). (g) TUNEL assay in 2-week-old proximal tibiae from control and Ikk $\beta^{\mathrm{F} / \mathrm{F}} ;$; Prx 1 -Cre mice. Apoptotic cells are indicated (red arrows). (h) Proximal tibiae from 2-week-old $I k k \beta^{\text {F/F; }}$ Prx 1 -Cre mice showed increased chondrocyte apoptosis in the chondroosseous junction ( $n=5$ in each group). ${ }^{*} P<0.05$ two-sided Student's $t$-test. Error bars \pm S.D. r, resting zone; $p$, proliferative zone; $h$, hypertrophic zone

the growth plate abnormalities in $I k k \beta^{\text {Prxiko }}$ mouse, we crossed $I k k \beta^{F / F}$ mice with transgenic mice that express Cre recombinase under the control of a type II collagen promoter. ${ }^{23,24} \mathrm{Ikk} \beta^{\mathrm{F} / \mathrm{F}}$;Col2a1-Cre (hereafter described as Ikk $\beta^{\text {Col2KO) }}$ mice were born at the expected Mendelian frequency and were viable and fertile. The deletion efficiency of the $1 \mathrm{kk} \beta^{\mathrm{F} / \mathrm{F}}$ locus in $I \mathrm{kk} \beta^{\mathrm{Col} 2 \mathrm{KO}}$ mice was assessed with genomic DNA isolated from primary rib chondrocytes by measuring the residual $I k k \beta$ locus. As shown in Figure $5 \mathrm{a}$, the amount of residual $I k k \beta$ locus was $3.4 \%$ in primary 


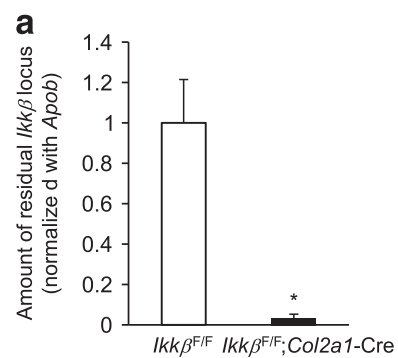

b

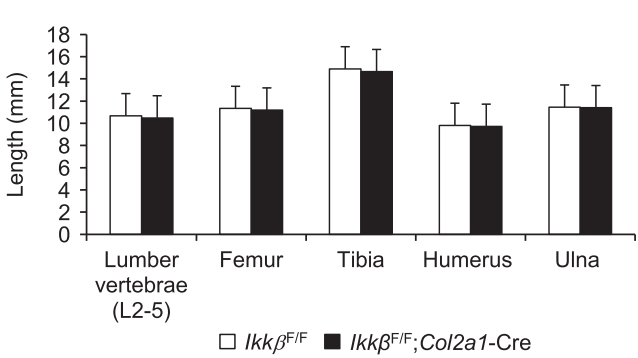

Figure $5 \quad \mathrm{IKK} \beta$ in chondrocytes is dispensable for endochondral ossification. (a) qPCR of residual $l k k \beta$ exon 3 with genomic DNA isolated from primary chondrocytes of control and $\mathrm{Ikk} \beta^{\mathrm{F} / F}$;Col2a1-Cre mice ( $n=3$ in each group) (b) Length of indicated bone of 8 -week-old $I \mathrm{kk}^{\mathrm{F} / \mathrm{F}} ;$ Col2a1-Cre mice $(n=5)$. ${ }^{*} P<0.001$, two-sided Student's $t$-test. Error bars \pm S.D.

chondrocytes isolated from $I k k \beta^{\mathrm{Col} 2 \mathrm{KO}}$, demonstrating that the deletion is quite effective. We examined the length of lumbar vertebrae and long bones until 8 weeks of age, but $I k k \beta^{\text {Col2KO }}$ mice did not show any growth retardation compared with control mice (Figure $5 b$ ). These results indicate that $\mathrm{IKK} \beta$ in cells committed to chondrocyte lineage is dispensable for normal bone growth in vivo.

Loss of IKK $\beta$ in the perichondrium causes aberrant expression of MCP-5. Reduced thickness of the hypertrophic zone in $I k k \beta^{\text {Prx1KO }}$ mice could be attributed to the loss of IKK $\beta$ in mesenchymal cells or their derivatives except for chondrocyte- and osteoblast-lineage cells. Cre recombinase has been reported to be expressed in the perichondrium from the Prx1 enhancer element but not from the type II collagen promoter. $^{23}$ Accordingly, we next focused on the perichondrium, which surrounds the cartilage and is known to synthesize essential factors that regulate endochondral bone growth $^{25-27}$ (reviewed in Kronenberg ${ }^{28}$ ). To examine gene expression in the perichondrium, we isolated RNA from proximal tibial perichondrium of 2-week-old wild-type, $I k k \beta^{\text {Col2KO }}$ and $I k k \beta^{\text {Prx1KO }}$ mice using laser capture microdissection (LCM). Figure 6a depicts the regions that were subjected to LCM. We confirmed that $I k k \beta$ in the perichondrium was specifically depleted in $I k k \beta^{\mathrm{Prx} 1 \mathrm{KO} O}$ but in neither

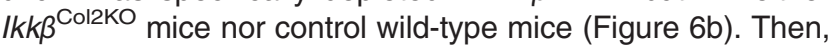
we examined the expression of genes encoding cytokines that were reported to affect endochondral ossification. ${ }^{17,29-31}$ As shown in Figure $6 \mathrm{c}$, among the cytokines examined, $/ 1-1 \beta$ and $M c p-5$ displayed big differences between $I k k \beta^{\text {Prx1KO }}$ and control mice. Although $\mathrm{IL}-1 \beta$ is reported to inhibit the differentiation of chondrocytes, ${ }^{29,32}$ it was downregulated in the perichondrium of $I k k \beta^{\text {Prx1KO }}$ mice and thus fails to explain the phenotype. Mcp-5, on the other hand, was upregulated 3.76-fold in $I k k \beta^{\text {Prx1KO }}$ compared with wild-type mice (Figure 6d). Recently, it was proposed that MCP-5 exerts a dual function during development of the joint and growth plate. $^{17}$ Of note, it was shown that MCP-5 blocks the progression of progenitor mesenchymal cells to chondrocyte hypertrophy and mineralization within the growth plate. Taking these previous findings into consideration, our observation of decreased chondrocyte hypertrophy in $I k k \beta^{\text {Prx1KO }}$ mouse could be explained by an increased production of MCP-5 in the perichondrium. Concordantly, by examining the expression of Ccr2 using RNA isolated from each zone of the growth plate by LCM, we found that Ccr2 can be detected in all zones of the growth plate, but significantly more so in the hypertrophic zone (Figure 6e). Important to note is that CCR2 is the sole receptor for MCP $-5 .^{33}$

MCP-5 can inhibit long bone growth ex vivo. These results prompted us to further investigate the role of MCP-5 on the growth of long bone. To this end, we performed tibial organ culture with or without recombinant mouse MCP-5. After 14 or 21 days of culture with recombinant MCP-5, the length of tibiae was significantly shorter than those of control (Figures $7 \mathrm{a}$ and $\mathrm{b}$ ). Histological examination of the bone cultured ex vivo confirmed that the effect on bone length was due to a decreased hypertrophic zone (data not shown), which is consistent with observations of $I k k \beta^{\mathrm{Prx} 1 \mathrm{KO}}$ mouse. To further investigate whether the effect of MCP-5 was exerted through the expression of CCR2 in the hypertrophic zone of the growth plate, we added RS-504393, a specific inhibitor of CCR2, to the ex vivo culture system. As shown in Figure 7c, the addition of RS-504393 cancelled the effect of MCP-5. This result supports the idea that $I \mathrm{KK} \beta$ loss in the perichondrium overproduces MCP-5, which then remotely affects the growth of long bone by disturbing chondrocyte hypertrophy in the growth plate.

IKK $\beta$ represses $M c p-5$ expression in a cell-autonomous manner independently of T $\beta$ RII and NF- $\boldsymbol{B}$ B. To investigate whether the repression of $M c p-5$ expression by $\mathrm{IKK} \beta$ is direct, and, if so, the underlying mechanism, we performed in vitro studies. We used mouse embryonal fibroblasts (MEFs) for this purpose, because they are of mesenchymal origin. We prepared MEFs from $I \mathrm{kk} \beta^{\mathrm{F} / \mathrm{F}}$ mice and used retroviralexpressed Cre recombinase to delete $I k k \beta$ exon 3 (Supplementary Figure S1a). We confirmed both the specificity (Supplementary Figure S4a) and the effectiveness (Supplementary Figure S4b) of the deletion. As shown in Figure $7 \mathrm{~d}$, deletion of $I k k \beta$ resulted in the upregulation of $M c p-5$, which is consistent with our observation in $I k k \beta^{\text {Prx1KO }}$ perichondrium. This result indicates that $\mathrm{IKK} \beta$ represses $M c p-5$ gene expression in a cell-autonomous manner. It was reported that T $\beta$ RII signaling also regulates $M c p-5$ expression during limb development. ${ }^{17}$ This fact led us to examine the effect of TGF- $\beta 1$ on the expression of $M c p-5$ and its relationship with $\mathrm{IKK} \beta$. As shown in Figure $7 \mathrm{~d}$, TGF- $\beta 1$ treatment resulted in the downregulation of $M c p-5$ in control (empty vector-treated) cells. Deletion of $I k k \beta$ did not affect this result, indicating that the repressive action of $\mathrm{IKK} \beta$ on $M c p-5$ expression is independent of TGF- $\beta$ signaling. We also 
a

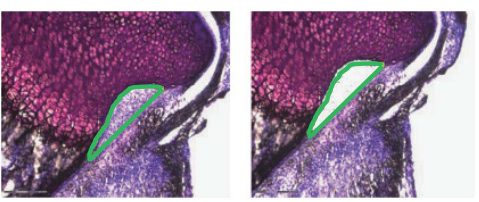

c

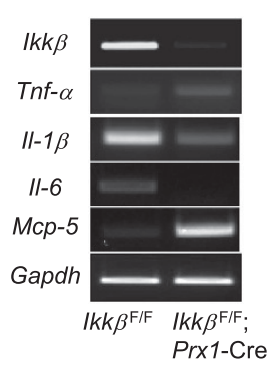

e

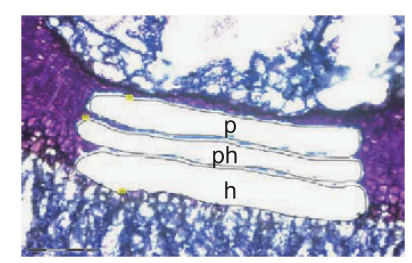

b

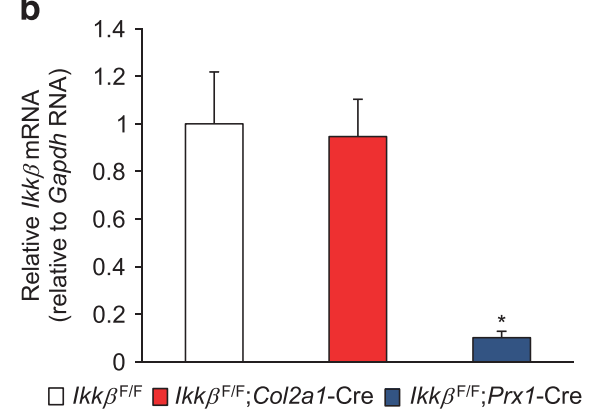

d
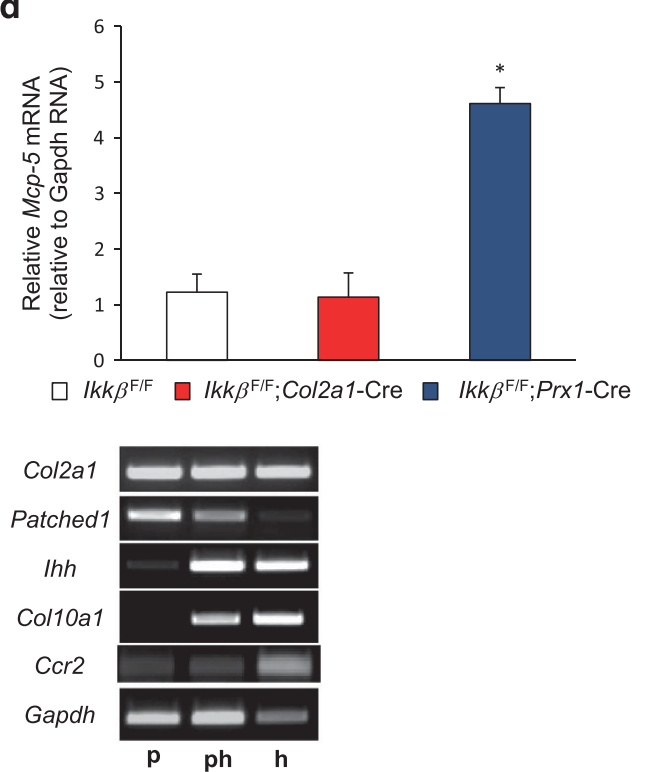

Figure 6 Loss of IKK $\beta$ in the perichondrium causes aberrant expression of Mcp-5. (a) Before and after LCM of 2-week-old proximal tibial perichondrium (depicted by the green lines). (b) $I k k \beta$ mRNA levels in the perichondrium of control, $I k k \beta^{\mathrm{F} F} ;$ Col2a1-Cre and $I k k \beta^{\mathrm{F} / F} ; \operatorname{Prx} 1$-Cre mice $(n=3$ in each group). (c) Cytokine expression in the perichondrium was analyzed with RNA prepared from microdissected samples by RT-PCR. PCR products were run on agarose gel and visualized. (d) qPCR analysis of Mcp-5 transcripts in the perichondrium of control, $I k k \beta^{F / F}$;Col2a1-Cre and $I k k \beta^{F / F}$;Prx1-Cre mice $\left(n=3\right.$ in each group). ${ }^{*} P<0.05$, two-sided Student's t-test. Error bars \pm S.D. (e) Expression of $\mathrm{Ccr} 2$ and markers for each zone of the growth plate. The region of each zone after LCM (left panel). Products of RT-PCR for transcripts are indicated (right panel). p, proliferation zone; ph, prehypertrophic zone; $h$, hypertrophic zone

investigated whether the effect of IKK $\beta$ is mediated through $N F-K B$, the major downstream effector of the IKK signalosome. For this purpose, we used $I_{k} \mathrm{~B} a(\mathrm{AA})$, also known as $I_{\kappa} B a$ super-repressor (SR). In $I_{\kappa} B a(S R)$, the serine 32 and 36 residues of $I_{\kappa} \mathrm{B} a$, the target phosphorylation sites for $\mathrm{IKK}$, are replaced with alanines, resulting in resistance to signalinduced degradation and consequent inhibition of NF- $k \mathrm{~B}$ activation. When a retroviral vector harboring $I_{\kappa} \mathrm{B} a(\mathrm{SR})$ was transduced into $I k k \beta^{\mathrm{F} / \mathrm{F}}-\mathrm{MEFs}$, the expression of $M c p-5$ was significantly reduced (Figure $7 d$ ). This result indicates that NF- $\kappa \mathrm{B}$ enhances the expression of $M c p-5$ in a signaldependent manner. Therefore, overall, our results suggest that IKK $\beta$ actively represses $M c p-5$ expression cell autonomously in a T $\beta$ RII- and NF- $\kappa \mathrm{B}$-independent manner.

\section{Discussion}

Here we report a new role of the IKK complex in bone formation. Contrary to expectations based on the well-known importance of cytokine signaling in the regulation of bone homeostasis, ${ }^{22,34}$ we found that IKK $\beta$ is dispensable in the osteoblast lineage during normal development and also for osteoprotection during postmenopausal osteoporosis. Chang et al. ${ }^{35}$ have reported that the inhibition of IKK in the osteoblast lineage by a dominant-negative form of the regulatory subunit IKK $\gamma$ (also known as NEMO), IKK $\gamma-D N$, expressed from the promoter of bone $\gamma$-carboxyglutamate protein-2 (Bglap2) or Col1a1 resulted in a substantial increase of trabecular bone mass and bone mineral density without affecting the activities of osteoclasts in young mice. ${ }^{35}$ In addition, they reported that osteobast lineage-specific expression of IKK $\gamma$-DN in mice prevented the osteoporotic bone loss induced by ovariectomy. ${ }^{35}$ Our different observations cannot be attributed to different genetic backgrounds of the mice, as they too used C57BL/6 mice. Moreover, we used the Col1a1 promoter to specifically drive Cre recombinase in the osteoblast lineage much like how they used it to drive IKKץ$\mathrm{DN}$, so the inconsistency is not because of differences in the stage of the osteoblast at which IKK was inactivated. The most plausible reason then for the inconsistency is that they overexpressed the IKKY-DN, whereas we conditionally 


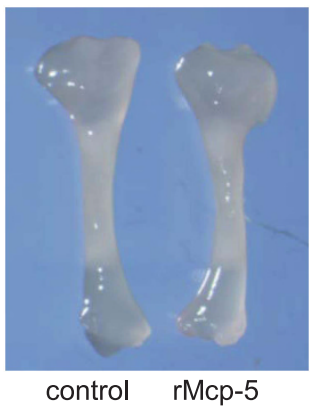

C

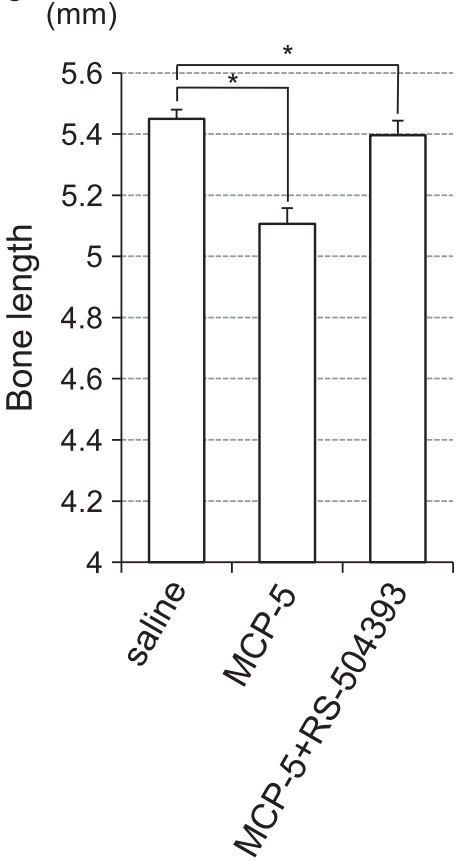

b

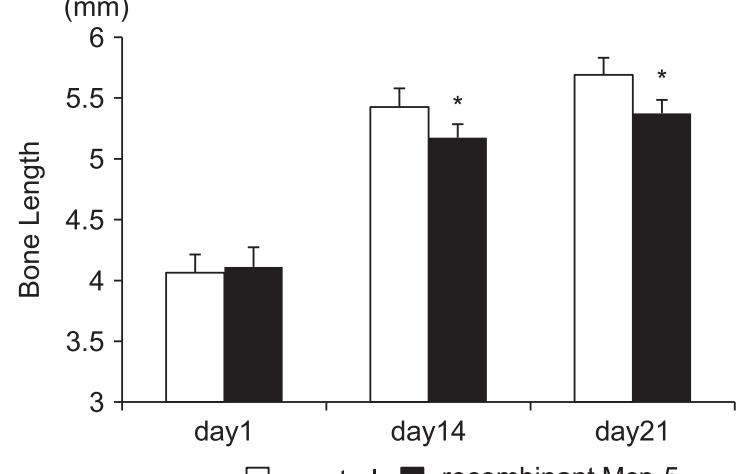

control

d
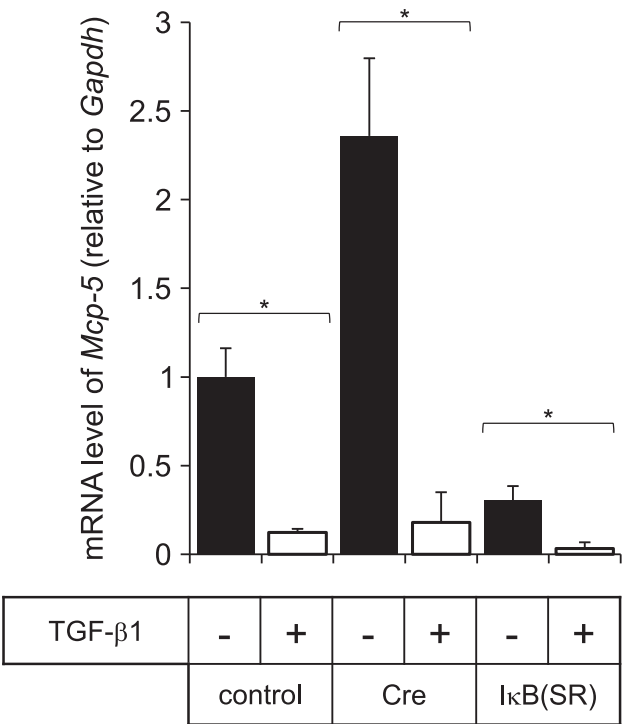

$\underline{I k k \beta^{\mathrm{F} / \mathrm{F}} \mathrm{MEF}}$

Figure 7 Ex vivo and in vitro experiments demonstrating retardation of bone growth by MCP-5 and the effect of IKK $\beta$ on $M c p-5$ expression is cell autonomous, respectively. (a) Representative photograph of tibia cultured ex vivo for 14 days. (b) Length of bone after explanted tibiae cultured for 1,14 and 21 days with or without $10 \mathrm{ng} / \mathrm{ml}$ of recombinant mouse Mcp-5 ( $n=6$ in each group). (c) Length of bone after explanted tibiae culture for 14 days with indicated reagents (mouse recombinant MCP-5, 10 ng/ml; RS-504393, $10 \mu \mathrm{M} ; n=5$ for each group). (d) $l \mathrm{kk} \beta^{\mathrm{F}} \mathrm{F}-\mathrm{MEF}$ s were infected with control (empty vector), Cre or $\mathrm{l} \mathrm{k} \mathrm{B}(\mathrm{SR})$ harboring retrovirus. At $24 \mathrm{~h}$ after infection, cells were treated with or without rhTGF- $\beta 1$ ( $2 \mathrm{ng} / \mathrm{ml}$ ) for $24 \mathrm{~h}$ and the mRNA level of Mcp- 5 was assessed by RT-qPCR ( $n=3$ for each sample). Data are representative of three independent experiments. ${ }^{*} P<0.05$, two-sided Student's t-test. Error bars \pm S.D.

deleted the gene encoding the catalytic subunit, IKK $\beta$. The C417R mutant of human IKKy (equivalent to C410R mutant of mouse), which Chang et al. ${ }^{35}$ used in their study, has been shown to serve as a dominant-negative mutant for cytokine-induced NF- $\kappa \mathrm{B}$ activation in human $\mathrm{T}$ cells, ${ }^{36}$ whereas NF- $k \mathrm{~B}$ activation by lipopolysaccharide is normal when this mutant is expressed in mouse $B$ cells. ${ }^{37}$ In addition, IKK $y$ has been shown to control the activation of JNK and p38 MAPK by cooperating with Ubc13 E2 ubiqutin-conjugating enzyme. $^{38}$ JNK and p38 MAPK are well-known cytokineresponsive MAPKs and are coordinatively activated with $\mathrm{NF}-\mathrm{KB}$ in response to a wide range of stimuli. Of note, JNK and p38 MAPK are also known to regulate Fra-1, which Chang et al. ${ }^{35}$ have shown is dysregulated in IKKy-DN-expressing cells. More recently, it was demonstrated that the expression of IKK mutants that allow for $\mathrm{IKK} \beta$ activation by $\mathrm{IL}-1 \beta$ but fail to recruit $I_{K} B s$ results in hyperphosphorylation of alternative $I K K \beta$ substrates. ${ }^{39}$ Therefore, it is highly possible that overexpression of IKK $\mathrm{K}$-DN might have altered the proper substrate specificity of the IKK complex to have evoked nonphysiological signaling as well as interference with MAPK activation.

Nevertheless, when $I k k \beta$ was conditionally deleted in limb bud mesenchymal cells, the longitudinal bone became shorter due to anomalies with chondrocyte hypertrophy in the growth plate. Therefore, it was surprising when we observed no abnormalities in either cartilage or bone of mice with chondrocyte-specific deletion of $I k k \beta$. Our results indicate that IKK $\beta$ has a role in chondrocyte hypertrophy in a non-cellautonomous manner. This conclusion begs the question, what could be the cause of the phenotype observed in $I k k \beta$ Prx1KO 
mice? Development of the limb skeleton starts with the condensation of undifferentiated mesenchymal cells in the limb bud, which is followed by the aggregated cells proceeding to chondrocyte lineage, whereas cells at the border of condensation form the perichondrium. ${ }^{22,40}$ The perichondrium is known to serve as a source of cytokines that regulate bone development. ${ }^{28}$ Among the cytokines known to affect chondrocytes, we found that MCP-5 is significantly upregulated in the perichondrium of $I k k \beta^{\text {Prx1KO }}$ mice. Mcp-5 is downregulated in embryonic joint-forming interzone cells. ${ }^{17}$ Moreover, conditional deletion of the gene encoding the T $\beta R I I$ in the limb bud mesenchyme (Tgfbr2 ${ }^{\mathrm{Prx} 1 \mathrm{KO}}$ ) has been shown to result in the upregulation of interzone-MCP-5, and Tgfbr2 ${ }^{\text {Prx1KO }}$ mice lacked joint development and failed at chondrocyte hypertrophy, suggesting that an unidentified signaling mechanism that represses the expression of $M c p-5$ in a T $\beta$ RII-independent manner counteracts interzone-MCP-5. ${ }^{17}$ We believe that IKK $\beta$ in the perichondrium is this mechanism.

Although our in vitro experiment demonstrated that repression of $M c p-5$ by $\mathrm{IKK} \beta$ is cell autonomous, details of the mechanism are still lacking. In the present study, we showed that the repression of $M c p-5$ is NF- $k \mathrm{~B}$-independent in unstimulated cells, but that the expression of $M c p-5$ can be upregulated in an NF-KB-dependent manner. It could be possible then that the IKK-NF-KB-MCP-5 signaling axis is involved in inflammatory bone diseases such as arthritis, in which cells are chronically exposed to a cytokine stream. Studies combining the use of an $I k k \beta$ conditional knockout (cKO) mutant and disease model mouse may provide an answer to this question.

In conclusion, our results illustrate a unique function of IKK $\beta$ in that it remotely controls growth plate development through the surrounding perichondrium (Supplementary Figure S5). This is intriguing because IKKa, the other catalytic subunit of IKK signalosome, has been shown to control skeletal morphogenesis through its action in the epidermis. ${ }^{41}$

\begin{abstract}
Materials and Methods
Animal studies. All animal experiments were approved by the Kyoto University Animal Care Committee. I kk $\beta^{\mathrm{F} F}$ mouse was described previously. ${ }^{10} \mathrm{Ikk} \beta^{\mathrm{F} F}$ mice were crossed with Prx1-Cre mice (purchased from Jackson Laboratories, Bar Harbor, ME, USA), Col1a1-Cre mice (obtained from Dr. S Kato, with permission from Dr. G Karsenty, Columbia University Medical Center, New York, NY, USA) and Col2a1-Cre mice (obtained from Dr. N Chano, Shiga University of Medical Science, Shiga, Japan). We genotyped offsprings by PCR using the following primers: Cre-for, 5'-TCCAATTTACTGACCGTACACCAA-3'; Cre-rev, 5'-CCTGATCCTGGCA ATTTCGGCTA-3'; IKK $\beta$-flox-for, 5'-GTCATTTCCACAGCCCTGTGA-3'; IKK $\beta$-flox-rev, $5^{\prime}$-CCTTGTCCTATAGAAGCACAAC-3'. The PCR product size was $220 \mathrm{bp}$
\end{abstract} (wild-type allele) and $310 \mathrm{bp}$ (floxed allele). ${ }^{10}$

Histology and histomorphometry. Hind limbs from 2-week-old $l k k \beta$ cKO and $I k k \beta^{F / F}$ control mice were dissected and used for paraffin and methylmethacrylate (MMA) embedding with and without decalcification, respectively.

For paraffin sections, we fixed tibiae for $20 \mathrm{~h}$ in $4 \%$ paraformalin, decalcified them in 20\% EDTA for 14 days, embedded them in paraffin and obtained $5 \mu \mathrm{m}$ sections. We stained the sections with safranin- $\mathrm{O}$ and used them for immunohistochemistry. For MMA sections, we fixed tibiae for $20 \mathrm{~h}$ in $4 \%$ paraformalin and embedded them in MMA. Toluidine blue and TRAP staining was performed on MMA sections.

The growth plate of proximal tibia histomorphometry was analyzed using Biorevo (Keyence, Osaka, Japan). Bone histomorphometry was analyzed using a bone morphology image analyzer (Histometry RT CAMERA; System Supply Co., Nagano, Japan).
Skeletal analysis. For alcian blue/alizarin red staining of whole skeletons, 1-day-old $I k k \beta \mathrm{cKO}$ and $I \mathrm{kk} \beta^{\mathrm{F} / \mathrm{F}}$ control mice were stained with alcian blue/alizarin red in glacial acetic acid and $70 \%$ ethanol. For three-dimensional bone volume and architecture of the distal femurs, we performed $\mu$ CT analysis (SMX-100CT-SV3; Shimadzu, Kyoto, Japan) and analyzed the data using the software VGStudio MAX2.0 (Nihon Visual Science Inc., Tokyo, Japan).

Immunohistochemistry. For immunohistochemistry, paraffin sections were rehydrated, and antigens were recovered by treatment with $10 \mu \mathrm{g} / \mathrm{ml}$ of proteinase $\mathrm{K}$ for $30 \mathrm{~min}$ at $37^{\circ} \mathrm{C}$. Sections were blocked with Protein Blocking (Dako, Tokyo, Japan) and incubated overnight at $4{ }^{\circ} \mathrm{C}$ with rabbit anti-type $\mathrm{X}$ collagen antibody (LSL, Tokyo, Japan). Alexa Fluor 555 (Invitrogen, Carlsbad, CA, USA) was used for secondary antibody, and sections were counter stained with DAPI.

BrdU and TUNEL assay. Two-week-old mice were injected intraperitoneally with $200 \mu \mathrm{l}$ ( $1 \mathrm{ml} / 100 \mathrm{~g}$ of body weight) of BrdU labeling reagent (Zymed Laboratories, South San Francisco, CA, USA) 20 and $4 \mathrm{~h}$ before killing. Incorporated $\mathrm{BrdU}$ was localized in proximal tibiae by immunohistochemistry using the BrdU Immunohistochemistry System (Chemicon, Darmstadt, Germany) according to the manufacturer's instructions. Apoptotic cells were detected using the TUNEL-based in situ Cell Death Detection Kit (Roche Diagnostics, Basel, Switzerland). After incubation with $10 \mu \mathrm{g} / \mathrm{ml}$ of proteinase $\mathrm{K}$ for $30 \mathrm{~min}$ at $37^{\circ} \mathrm{C}$, sections were incubated with the TUNEL reaction mixture for $2 \mathrm{~h}$ at $37^{\circ} \mathrm{C}$ and mounted with Fluorescence Mounting Medium (Dako).

Microdissection and qPCR. For growth plate chondrocytes and perichondrium, $\sim 40$ of $30 \mu \mathrm{m}$ frozen sections were prepared from tibiae of 2-week-old $l \mathrm{kk} \beta$ $\mathrm{cKO}$ and $I k k \beta$ floxed mice. Morphologically distinct groups of cells in growth plates were microdissected using PALM MicroBeam (Zeiss, Jena, Germany) and collected in lysis buffer RLT plus reagent (Qiagen, Venlo, Netherlands), and total RNA was extracted with the RNeasy Micro Plus Kit (Qiagen). The quality of RNA was checked with the 2100 Bioanalyzer (Agilent Technologies, Santa Clara, CA, USA). Total RNA was reverse-transcribed with SuperScript III (Invitrogen), and one-tenth of the CDNA was amplified by the $\mathrm{ABI}$ Prism 7000 sequence detection system (Applied Biosystems) using SYBRgreen (Applied Biosystems, Foster City, CA, USA). Results were normalized to the endogenous expression of Gapdh, and the fold expression was calculated with the $2-\Delta \Delta C T$ method. Conditions for PCR and qPCR are available upon request.

Residual Ikk $\boldsymbol{\beta}$ locus. To evaluate the deleted $(I k k \beta \Delta)$ or residual Ikk $\beta$ locus by real-time PCR, a segment of genomic DNA lying at loxP sites or exon 3 , respectively, was amplified. ${ }^{19}$ Schematic representation of the $1 \mathrm{kk} \beta$ locus and primers are shown in Supplemetary Figure S1a.

Ovariectomy. Twelve-week-old female $I K K \beta \mathrm{cKO}$ and $I k k \beta^{\mathrm{F} / \mathrm{F}}$ control mice were ovariectomized or sham operated. After 8 weeks, all mice were killed and subjected to bone analysis.

Organ culture. Tibiae from 1-day-old mice were harvested and cultured in $\alpha$-MEM medium (Gibco, Carlsbad, CA, USA) supplemented with $10 \%$ FBS for the days indicated in $37^{\circ} \mathrm{C} / 5 \% \mathrm{CO}_{2}$. Mouse recombinant Mcp-5 (Cosmo Bio Co., Ltd, Tokyo, Japan) and RS-504393 (Tocris Bioscience, Minneapolis, MN, USA) were added at the indicated final concentrations. Medium was changed every 3 days.

Cells and reagents. MEFs were established from $1 k k \beta^{\mathrm{F} / F}$ embryos by dissecting E14.5 embryos and maintained in Dulbecco's modified Eagle's medium (DMEM) (4.5 g/l glucose) (Nacalai Tesque, Kyoto, Japan) supplemented with $10 \%$ FBS. Retroviral vector pMGP-Cre, pMXs-I $\kappa \alpha^{(\mathrm{AA})}$ and pMXs were transfected to Plat$\mathrm{E}$ cells (generously provided by Dr. T Kitamura) to produce the viral supernatants.

Isolation of primary chondrocytes and osteoblasts. Primary chondrocytes were isolated as described previously. ${ }^{42}$ Briefly, costal cartilage of 5-day-old mice was digested with collagenase D and cultured in DMEM (SigmaAldrich, St. Louis, MO, USA) supplemented with $10 \%$ fetal bovine serum. Primary osteoblasts were isolated from neonatal mouse calvaria as described previously. ${ }^{43}$ Calvariae were dissected from neonatal (P2) pups (2nets) and incubated in $4 \mathrm{ml}$ of digestion solution ( $3.2 \mathrm{mg}$ of collagenase type II (Gibco) per $1 \mathrm{ml}$ of trypsin solution) at $37^{\circ} \mathrm{C}$ for $20 \mathrm{~min}$. The supernatant was then transferred to a new tube, and $700 \mu \mathrm{l}$ of FBS was added to inhibit trypsin activity. The calvaria were washed with $3 \mathrm{ml}$ of 
DMEM (without FBS), shaken well and added to the supernatant of the tube containing the cell suspension. Cells were collected by centrifugation, resuspended in complete culture medium (DMEM supplemented with $100 \mu \mathrm{g} / \mathrm{ml}$ of ascorbate, 10\% FBS (HyClone, Logan, UT, USA) and antibiotic-antimycotic (Gibco)) and seeded into 6-well plates. The procedure was repeated four times.

Statistical analysis. Statistical analyses were performed using Student's $t$-test. A $P$-value of $<0.05$ was considered statistically significant.

\section{Conflict of Interest}

The authors declare no conflict of interest.

Acknowledgements. We are indebted to Dr. M Hibi (Nagoya University) for critically reading of the manuscript. We also thank Peter Karagiannis (CiRA, Kyoto University) for help in preparing the manuscript. We thank Dr. G Karsenty for permitting us to use the Col1a1-Cre Tg mouse and Dr. S Kato for providing it, and Dr. T Chano for providing the Col2a1-Cre Tg mouse and Dr. T Kitamura (The University of Tokyo) for providing Plat-E cells. Finally, we thank members of the Toguchida Lab, especially M Ikeya, Y Jin, S Sato, S Tamaki, N Takahara and Y Kobayashi, for their help. This work was supported by Grant-in-Aid for Scientific Research from the Ministry of Education, Culture, Sports, Science and Technology of Japan (21591941 to TK Jr)

\section{Author contributions}

TK Jr, MK and JT conceived the project. KK and TK Jr designed and performed the experiments. KK and TK Jr analyzed the data and wrote the manuscript. MK edited the manuscript. JT supervised the project.

1. Rothwarf DM, Karin M. The NF-kappa B activation pathway: a paradigm in information transfer from membrane to nucleus. Sci STKE 1999; 1999: RE1.

2. Hacker H, Karin M. Regulation and function of IKK and IKK-related kinases. Sci STKE 2006; 2006: re13.

3. Karin M, Ben-Neriah Y. Phosphorylation meets ubiquitination: the control of NF-[kappa]B activity. Annu Rev Immunol 2000; 18: 621-663.

4. Hayden MS, Ghosh S. Shared principles in NF-kappaB signaling. Cell 2008; 132 344-362.

5. Chariot A. The NF-kappaB-independent functions of IKK subunits in immunity and cancer. Trends Cell Biol 2009; 19: 404-413.

6. Hinz M, Scheidereit $\mathrm{C}$. The IkappaB kinase complex in NF-kappaB regulation and beyond. EMBO Rep 2014; 15: 46-61.

7. Li ZW, Chu W, Hu Y, Delhase M, Deerinck T, Ellisman M et al. The IKKbeta subunit of IkappaB kinase (IKK) is essential for nuclear factor kappaB activation and prevention of apoptosis. J Exp Med 1999; 189: 1839-1845.

8. Tanaka M, Fuentes ME, Yamaguchi K, Durnin MH, Dalrymple SA, Hardy KL et al. Embryonic lethality, liver degeneration, and impaired NF-kappa B activation in IKK-beta-deficient mice. Immunity 1999; 10: 421-429.

9. Li Q, Van Antwerp D, Mercurio F, Lee KF, Verma IM. Severe liver degeneration in mice lacking the IkappaB kinase 2 gene. Science 1999; 284: 321-325.

10. Li ZW, Omori SA, Labuda T, Karin M, Rickert RC. IKK beta is required for peripheral B cell survival and proliferation. J Immunol 2003; 170: 4630-4637.

11. Pasparakis M, Courtois G, Hafner M, Schmidt-Supprian M, Nenci A, Toksoy A et al. TNF-mediated inflammatory skin disease in mice with epidermis-specific deletion of IKK2. Nature 2002; 417: 861-866.

12. Karsenty G. The complexities of skeletal biology. Nature 2003; 423: 316-318.

13. Karsenty $G$, Wagner EF. Reaching a genetic and molecular understanding of skeletal development. Dev Cell 2002; 2: 389-406.

14. Teitelbaum SL, Ross FP. Genetic regulation of osteoclast development and function. Nat Rev Genet 2003; 4: 638-649.

15. Boyle WJ, Simonet WS, Lacey DL. Osteoclast differentiation and activation. Nature 2003; 423: 337-342.

16. Ruocco MG, Maeda S, Park JM, Lawrence T, Hsu LC, Cao Y et al. I\{kappa\}B kinase (IKK) \{beta\}, but not IKK\{alpha\}, is a critical mediator of osteoclast survival and is required for inflammation-induced bone loss. J Exp Med 2005; 201: 1677-1687.
17. Longobardi L, Li T, Myers TJ, O'Rear L, Ozkan H, Li Y et al. TGF-beta type II receptor/MCP-5 axis: at the crossroad between joint and growth plate development. Dev Cell 2012; 23: 71-81.

18. Dacquin R, Starbuck M, Schinke T, Karsenty G. Mouse alpha1(I)-collagen promoter is the best known promoter to drive efficient Cre recombinase expression in osteoblast. Dev Dyn 2002; 224: 245-251.

19. Egan LJ, Eckmann L, Greten FR, Chae S, Li ZW, Myhre GM et al. IkappaB-kinasebetadependent NF-kappaB activation provides radioprotection to the intestinal epithelium. Proc Natl Acad Sci U S A 2004; 101: 2452-2457.

20. Inada M, Matsumoto C, Miyaura C. Animal models for bone and joint disease. Ovariectomized and orchidectomized animals. Clin Calcium 2011; 21: 164-170.

21. Logan M, Martin JF, Nagy A, Lobe C, Olson EN, Tabin CJ. Expression of Cre Recombinase in the developing mouse limb bud driven by a Prxl enhancer. Genesis 2002; 33: 77-80.

22. Kronenberg HM. Developmental regulation of the growth plate. Nature 2003; 423: 332-336.

23. Ovchinnikov DA, Deng JM, Ogunrinu G, Behringer RR. Col2a1-directed expression of Cre recombinase in differentiating chondrocytes in transgenic mice. Genesis 2000; 26: 145-146.

24. Nishimura I, Chano T, Kita H, Matsusue Y, Okabe H. RB1CC1 protein suppresses type II collagen synthesis in chondrocytes and causes dwarfism. J Biol Chem 2011; 23286: 43925-43932.

25. Long $F$, Linsenmayer TF. Regulation of growth region cartilage proliferation and differentiation by perichondrium. Development 1998; 125: 1067-1073.

26. Alvarez J, Horton J, Sohn P, Serra R. The perichondrium plays an important role in mediating the effects of TGF-beta1 on endochondral bone formation. Dev Dyn 2001; 221: 311-321.

27. Colnot C, Lu C, Hu D, Helms JA. Distinguishing the contributions of the perichondrium, cartilage, and vascular endothelium to skeletal development. Dev Biol 2004; 269: 55-69.

28. Kronenberg HM. The role of the perichondrium in fetal bone development. Ann NY Acad Sci 2007; 1116: 59-64

29. Martensson K, Chrysis D, Savendahl L. Interleukin-1beta and TNF-alpha act in synergy to inhibit longitudinal growth in fetal rat metatarsal bones. J Bone Miner Res 2004; 19 : 1805-1812.

30. De Benedetti F, Rucci N, Del Fattore A, Peruzzi B, Paro R, Longo M et al. Impaired skeletal development in interleukin-6-transgenic mice: a model for the impact of chronic inflammation on the growing skeletal system. Arthritis Rheum 2006; 54: 3551-3563.

31. MacRae VE, Farquharson C, Ahmed SF. The restricted potential for recovery of growth plate chondrogenesis and longitudinal bone growth following exposure to pro-inflammatory cytokines. J Endocrinol 2006; 189: 319-328.

32. Sederquist B, Fernandez-Vojvodich P, Zaman F, Savendahl L. Impact of inflammatory cytokines on longitudinal bone growth. J Mol Endocrinol Apr 2014; 53: T35-T44.

33. Sarafi MN, Garcia-Zepeda EA, MacLean JA, Charo IF, Luster AD. Murine monocyte chemoattractant protein (MCP)-5: a novel CC chemokine that is a structural and functional homologue of human MCP-1. J Exp Med 1997; 185: 99-109.

34. Marie PJ. Signaling pathways affecting skeletal health. Curr Osteoporos Rep Sep 10: 190-198.

35. Chang J, Wang Z, Tang E, Fan Z, McCauley L, Franceschi R et al. Inhibition of osteoblastic bone formation by nuclear factor-kappaB. Nat Med 2009; 15: 682-689.

36. Yang F, Yamashita J, Tang E, Wang HL, Guan K, Wang CY. The zinc finger mutation C417R of I-kappa B kinase gamma impairs lipopolysaccharide- and TNF-mediated NF-kappa B activation through inhibiting phosphorylation of the I-kappa B kinase beta activation loop. J Immunol 2004; 172: 2446-2452.

37. Huang TT, Feinberg SL, Suryanarayanan S, Miyamoto S. The zinc finger domain of NEMO is selectively required for NF-kappa B activation by UV radiation and topoisomerase inhibitors. Mol Cell Biol 2002; 22: 5813-5825.

38. Yamamoto M, Okamoto T, Takeda K, Sato S, Sanjo H, Uematsu S et al. Key function for the Ubc13 E2 ubiquitin-conjugating enzyme in immune receptor signaling. Nat Immuno/ 2006; 7: 962-970.

39. Schrofelbauer B, Polley S, Behar M, Ghosh G, Hoffmann A. NEMO ensures signaling specificity of the pleiotropic IKKbeta by directing its kinase activity toward IkappaBalpha. Mol Cell 2012; 47: 111-121.

40. Akiyama H, Kim JE, Nakashima K, Balmes G, Iwai N, Deng JM et al. Osteo-chondroprogenitor cells are derived from Sox9 expressing precursors. Proc Natl Acad Sci US A 2005; 102: 14665-14670.

41. Sil AK, Maeda S, Sano Y, Roop DR, Karin M. IkappaB kinase-alpha acts in the epidermis to control skeletal and craniofacial morphogenesis. Nature 2004; 428: 660-664.

42. Gosset M, Berenbaum F, Thirion S, Jacques $C$. Primary culture and phenotyping of murine chondrocytes. Nat Protoc 2008; 3: 1253-1260.

43. Bakker A, Klein-Nulend J. Osteoblast isolation from murine calvariae and long bones. Methods Mol Med 2003; 80: 19-28. 